\title{
Synthesis and Characterization of Acetylated Cassava Starch with Different Degrees of Substitution
}

\author{
Valeria Daiana Trela ${ }^{*}$ \\ https://orcid.org/0000-0003-3408-6618
}

Ana Laura Ramallo ${ }^{1}$

https://orcid.org/0000-0001-8334-3882

\section{Oscar Alfredo Albani ${ }^{1}$}

https://orcid.org/0000-0002-6375-1309

IIMAM (CONICET-Universidad Nacional de Misiones) and FCEQYN-UNaM, Posadas, Misiones, Argentina

Received: 2018.06.10; Accepted: 2019.08.06.

* Correspondence: valeriatrela@gmail.com; Tel.: +54-3754458145 (V.T.)

\section{HIGHLIGHTS}

- Acetylated cassava starch with degree of substitution (DS) between 0.04 and 1.36 was synthesized.

- Two methods of acetylation were used to obtain a wide range of DS.

- Swelling power, solubility, clarity and pasting temperature varied with DS of acetylated starch.

- SEM micrographs showed the effect of DS on starch granules integrity.

\begin{abstract}
Acetylated cassava starch with low and medium degrees of substitution (DS) were synthesized. Also, the effect of DS on swelling power, solubility, morphological properties, gelatinization temperature, paste clarity and moisture sorption were studied. Swelling power and solubility in water between $50^{\circ} \mathrm{C}$ and $90^{\circ} \mathrm{C}$ were determined. Acetylated cassava starches with low DS showed an increased in both parameters, while at higher DS values a reduction of them was observed. Maximum swelling power values were measured in acetylated starch with DS of 0.2 and maximum solubility was registered at DS of 0.72 . Equilibrium moisture content values from sorption isotherms presented a good fit using the GAB model (R2>0.96). SEM micrographs showed that as acetyl groups are incorporated the granules suffer surface changes and eventually lose their structure at DS of 1.5. Clarity of acetylated starch pastes with low DS was lighter than native starch paste. In addition, the increase in DS produced a reduction in gelatinization temperature.
\end{abstract}

Keywords: cassava starch, acetylation, physicochemical properties.

\section{INTRODUCTION}

Starch modification, which implies the alteration of the physical and chemical characteristics of native starch, is used to improve its functional characteristics and adapt it to specific applications. A common and widely used modification in starch is acetylation that is the esterification with acetyl groups to form acetates [1].

Acetylated starch is classified according to its degree of substitution (DS). Starches with low DS $(<0.2)$ are commonly used in the food industry, since they confer consistency, texture and stability, to baked goods, cake fillings, sauces and soups. Starches with medium DS $(>1.0)$ are used as cellulose acetate substitutes [2]. Starches with high DS (2-3) are characterized by their thermoplasticity and their solubility in organic 
solvents such as acetone and chloroform have been used for non-food applications such as adhesives, coatings, biodegradable plastics and pharmaceutical applications [3, 4].

Cassava is a native crop of tropical America. It is cultivated in different regions of America, Asia and Africa. The main cultivated area of cassava in Argentina is the province of Misiones. Part of this production is destined to supply the market for human food as fresh cassava and the other is destined to production of flour and starch.

Several researches were done relate to changes in the properties of acetylated starches in different range of degree of substitution, involving varied sources of starch. However, few studies are based on cassava starch and the range of DS in each study was limited by the applied acetylation methodology. Singh et al. [5] studied the effect of acetylation on some properties of corn and potato starches in a range of DS $0.104-0.154$. In other works, the effect of starch acetylation from different rice cultivars in a range of DS $0.107-0.144$ were studied [6]. Colussi et al. [7] studied the effect of acetylation on the properties of low, medium and high amylose rice starch. Mello El Halal et al. [8] studied the effect of different catalyst concentrations on the acetylation reaction of barley starch. Xu et al. [3] carried out the synthesis and characterization of acetylated maize starch with DS between 0.57-2.59.

Mbougueng et al. [9] studied the influence of acetylation time on physico-chemical, functional and thermal properties of cassava and potato starches in a DS range lower than 0.26. Osundahunsi et al. [10] studied the effect of acetic anhydride on the acetylation reaction of two cassava species in the DS range of 0.03 and 0.213 . Larotonda et al. [11] used acetylation reaction in acid medium to obtain acetilated cassava starch with degrees of substitution in the range of 1.22 and 1.56 to made biodegradable films.

Osundahunsi et al. [10] working with acetylated cassava starches, observed that the swelling power and solubility increased with the degree of substitution. Mbougueng et al. [9] studying potato and cassava starch found that for DS between 0 and 0.26 the solubility increased as a function of DS. They also found that the clarity of acetylated starch pastes increased with respect to the native one and in the cassava starch, it increased with the DS. Diop et al. [12] observed that the solubility decreases as a function of DS in a range (1.83-2.9) in corn starch. This complex relationship of the physicochemical properties of acetylated starches with degree of substitution makes necessary a systematic study of the characteristics of acetylated cassava starch covering a wide range of degree of substitution, as it is intended in this study.

The aim of the present work was synthesize acetylated cassava starch with low and medium substitution degree using two different acetylation methods. Also the effect of DS on swelling power, solubility, morphological properties, gelatinization temperature, pasta clarity and moisture sorption where studied.

\section{MATERIAL AND METHODS}

\section{Synthesis of acetylated cassava starch}

Cassava starch was obtained from ALDEMA®, an industrial plant located in Misiones, Argentina. Samples were stored in oven at $60^{\circ} \mathrm{C}$ for 48 hours to standardize the moisture content. All chemicals used in this work were of analytical grade. Acetylated cassava starch was synthesized by two methods to obtain different degrees of substitution.

\section{Low degree starch acetate ( $D S<0.2)$}

An adaptation of method developed by Wurzburg [13] was used: $50 \mathrm{~g}$ of cassava starch and $112.5 \mathrm{~mL}$ of distilled water were mixed using a magnetic stirrer. The $\mathrm{pH}$ was maintained at $8.0-8.5$ using a $3 \% \mathrm{NaOH}$ solution. Acetic anhydride was then added drop wise. After the addition of acetic anhydride was complete, the system was maintained with vigorous stirring and constant temperature $\left(25^{\circ} \mathrm{C}\right)$ for $30 \mathrm{~min}$. To stop the reaction, the $\mathrm{pH}$ was lowered to 4.5 with $0.5 \mathrm{~mol} / \mathrm{L} \mathrm{HCl}$. It was rinsed once with ethanol and 3 times with distilled water. Then was filtered and oven dried at $40{ }^{\circ} \mathrm{C}$ for $48 \mathrm{~h}$.

To obtain samples with different DS the amount of added acetic anhydride was varied between 2 and 20 $\mathrm{g} / 100 \mathrm{~g}$ starch, as is shown in Table 1.

\section{Intermediate degree starch acetate $(0.2<D S<1.5)$}

The method of Mark and Mehltretter [14] was used with some modifications. Native starch (40 g) were dispersed in acetic anhydride in a weight ratio of $1 / 2$ and 1/3. A magnetic stirrer was used to keep homogeneous the suspension. Required volume of $50 \% \mathrm{NaOH}$ solution was then added drop wise to obtain 
the corresponding DS. Temperature was then increased to $123^{\circ} \mathrm{C}$ in $15 \mathrm{~min}$. The reaction was carried out during 30, 60, 105 and 240 min, maintaining vigorous stirring. Excess cold water was added to stop the reaction. It was allowed to settle, rinsed 3 times. Finally it was filtered and oven dried at $40^{\circ} \mathrm{C}$ for 48 hours.

With this method two groups of experimental tests were carried out. In one assay group the reaction time was varied, keeping constant the ratio starch / acetic anhydride $(1: 3 \mathrm{~g} / \mathrm{g})$ and catalyst amount $(0.107 \mathrm{~g}$ of $\mathrm{NaOH}$ solution $/ \mathrm{g}$ starch). In another set, the ratio $\mathrm{NaOH}$ solution $/$ starch was varied $(0.05,0.1$ and $0.2 \mathrm{~g} / \mathrm{g}$ ), with constant ratio starch / acetic anhydride (1/2 g/g) and reaction time (30 $\mathrm{min})$, as is showed in Tables 2 and 3.

\section{Determination of acetyl percentage and degree of substitution}

\section{Degree of substitution (DS) $<0.2$}

To evaluate the degree of substitution, the technique developed by Ogawa et al. [15] was used. Acetylated starch $(5 \mathrm{~g})$ were weighed and dispersed in $50 \mathrm{~mL}$ of distilled water. To neutralize the mixture a few drops of $0.1 \mathrm{~mol} / \mathrm{L} \mathrm{NaOH}$ were added, using phenolphthalein as indicator. Then $25 \mathrm{~mL}$ of $0.45 \mathrm{~mol} / \mathrm{L}$ $\mathrm{NaOH}$ was added and the mixture was stirred for $30 \mathrm{~min}$, with the Erlenmeyer capped to prevent evaporation. Finally, the excess alkali was neutralized with a $0.2 \mathrm{~mol} / \mathrm{L} \mathrm{HCl}$. A blank test (native starch) following the same procedure was performed. The preparations were carried out by triplicate. The acetyl percentage (\% Ac) was calculated with Equation (1).

$$
\% \text { Ac }=\frac{(\text { Blank }- \text { Sample }) \times \mathrm{N}_{\mathrm{HCl}} \times 43 \times 100}{\text { sample weight }}
$$

Blank and sample titration volumes were expressed in $\mathrm{mL}$, sample weight was expressed in $\mathrm{mg}$ and $\mathrm{NHCl}$ was the normality of $\mathrm{HCl}$.

DS was calculated with Equation (2).

$$
\mathrm{DS}=\frac{162 \times\left(\frac{\% \mathrm{Ac}}{43}\right)}{100-\left(\frac{42}{43} \times \% \mathrm{Ac}\right)}
$$

\section{Degree of substitution (DS) $>0.2$}

Degree of substitution (>0.2) was determined according to Xu et al. [2]. Native starch $(0.5 \mathrm{~g})$ was weighed and placed in Erlenmeyer flask with $50 \mathrm{~mL}$ of distilled water. Then, $25 \mathrm{~mL}$ of $0.5 \mathrm{~mol} / \mathrm{L} \mathrm{NaOH}$ was added and the sample was heated in thermostated bath (Vicking, Model Dubnoff 5002 , Argentine) at $50{ }^{\circ} \mathrm{C}$ for 30 min until a clear solution was obtained. It was allowed to stand to complete the saponification for $72 \mathrm{~h}$ with eventual stirring. Finally, the excess $\mathrm{NaOH}$ was titrated with $0.5 \mathrm{~mol} / \mathrm{L} \mathrm{HCl}$. The preparations were carried out by triplicate. The DS was calculated with Equation (3).

$$
\mathrm{DS}=\frac{162 *\left(\mathrm{~N}_{\mathrm{NaOH}} * V_{\mathrm{NaOH}}-N_{\mathrm{HCl}} * V_{\mathrm{HCl}}\right)}{1000 * W-42 *\left(N_{\mathrm{NaOH}} * V_{\mathrm{NaOH}}-N_{\mathrm{HCl}} * V_{\mathrm{HCl}}\right)}
$$

\section{FTIR Analysis}

For FTIR discs, acetylated and native starch powder was mixed in a mortar with $\mathrm{KBr}$ in relation 10:1 (g/g), to obtain fine and homogeneous particles. IR spectra were obtained using a Perkin Elmer FT-IR spectrometer, GX model (USA). The scanning was performed in a wave numbers from 4000 to $550 \mathrm{~cm}-1$.

\section{Swelling power (SP) and water solubility index (WSI)}

The swelling power and solubility of the starches were determined as described by Leach et al. [16] with minor modifications [7]. Sample $(1 \mathrm{~g})$ was dispersed in $50 \mathrm{~mL}$ of distilled water in a centrifuge tube. Suspension was shaken and then taken to a bath, maintaining a constant temperatures $(50,60,70,80 \mathrm{y}$ $90{ }^{\circ} \mathrm{C}$ ) for $30 \mathrm{~min}$. It was a cooled at room temperature and centrifuged at $5000 \mathrm{rpm}$ for $30 \mathrm{~min}$. The capsule with supernatant was placed in an oven at $103 \pm 1^{\circ} \mathrm{C}$ until constant weight to quantify the soluble fraction. WSI was expressed as percentage of dry soluble weight respect to dry sample weight. SP was calculated as the mass ratio of the wet sediment to the initial dry sample, deducting the amount of soluble starch. 


\section{Scanning electron microscopy (SEM)}

Morphologies of native starch and starch acetates were observed using SEM (JEOL 35 CF, Japan). Before testing, samples were mounted on the stub with double-sided adhesive tapes and coated with gold to make the sample conductive. Images were taken at an accelerating voltage of $15 \mathrm{kV}$ and magnification of $457 \mathrm{X}$ and $1.14 \mathrm{kX}$.

\section{Moisture sorption isotherm}

To determine the sorption isotherms of cassava starch with different DS (NS, $A S_{0,08}, A_{0,88}, A_{1,04}$ and $A S_{1,28}$ ), static gravimetric method was used. Approximately $2 \mathrm{~g}$ of starch, previously dried in silica gel during one week, were placed in petri dish inside closed chamber at constant humidity. Each essay was carry out by triplicate. The aw range of $0.113-0.936$ was obtained with following salts: $\mathrm{LiCl}, \mathrm{MgCl}_{2}, \mathrm{Mg}\left(\mathrm{NO}_{3}\right)_{2}, \mathrm{NaBr}$, $\mathrm{CoCl}_{2}, \mathrm{NaNO}_{3}, \mathrm{NaCl}$ and $\mathrm{KNO}_{3}$. Chambers were kept at $25 \pm 1^{\circ} \mathrm{C}$ until equilibrium was attained. Experimental data were adjusted employing GAB (Guggenheim, Anderson y De Boer) sorption equation (Equation 4) and non-linear regression statistical analysis was performed.

$$
X=\frac{X_{m} C k a_{w}}{\left(1-k a_{w}\right)\left(1-k a_{w}+C k a_{w}\right)}
$$

Where $\mathrm{Xm}$ is the monolayer moisture content and $\mathrm{C}$ and $\mathrm{k}$ are constants [15].

Mean percentage error (MPE) was calculated using Equation 5.

$$
M P E=\frac{\sum \frac{\left|X_{\text {expeimental }-X_{\text {calculated }} \mid}\right|}{X_{\text {expeimental }}}}{N}
$$

Where $\mathrm{N}$ is the number of experimental data.

\section{Starch pasting properties}

\section{Paste clarity}

Starch paste clarity was determined using the technique of Piyachomkwan et al.[17] with few modifications. Aqueous suspensions of $4 \% \mathrm{w} / \mathrm{w}$ starch were gelatinized for $20 \mathrm{~min}$ in a water bath at $90^{\circ} \mathrm{C}$. Then, it was allowed to cool to room temperature and transmittance was measured at $650 \mathrm{~nm}$, using distilled water as reference. A UV-Vis spectrophotometer was used (UV model: 2550, Shimadzu, Japan). Assays were performed in triplicate and results were expressed as light transmittance percentage (paste clarity).

\section{Viscoamylographic test}

The pasting properties of the starch samples were determined by Micro-Visco-Amylo-Graph (Brabender $\mathrm{GmbH}$, Germany). An adaptation of the ISI 19-6e [18] standard was used.

Suspensions of native and modified starch (5 g/g solution) were prepared. The equipment was programmed to run a heating-cooking-cooling cycle that began at $50{ }^{\circ} \mathrm{C}$ and then increased to $95{ }^{\circ} \mathrm{C}$, keeping at this temperature for $30 \mathrm{~min}$, then cooled down to $50{ }^{\circ} \mathrm{C}$ and maintained at this temperature for another 5 min. A heating and cooling rate of $3{ }^{\circ} \mathrm{C} / \mathrm{min}$ was used throughout the cycle. The following characteristic values of temperature and viscosity were recorded: pasting temperature (PT), peak viscosity (PV), hot paste viscosity (HPV) at $95^{\circ} \mathrm{C}$, cool paste viscosity (CPV) at $50{ }^{\circ} \mathrm{C}$, breakdown (BD = HPV-PV), and setback (SB = PV-HPV). Viscosity was expressed in unit Brabender (UB).

\section{Statistical analysis}

Results obtained from analytical determinations was analyzed using the least significant difference (LSD) multiple range test with a significance level $\alpha=0.05$. The Stat Graphics $₫(2009)$ statistical package was used to process the data. 


\section{RESULTS}

\section{Acetyl percentage and degree of substitution}

\section{a) Degree of substitution $<0.2$}

Percentage of acetyl group and degree of substitution of acetylated cassava starch obtained by Wurzburg [11] method as function of acetic anhydride volume added are presented in Table 1. Samples were labeled according to the degree of substitution. Values shown in Table 1 are means of triplicate determinations \pm standard deviation.

The variation of DS of acetylated starches with the concentration of acetic anhydride adjusted to a linear relationship with $R^{2}=0.96$.

Acetylated starch prepared with less than $10 \mathrm{~g}$ acetic anhydride/100 $\mathrm{g}$ starch, presented values of DS between $0.04(1.05 \% \mathrm{Ac})$ and $0.10(2.50 \% \mathrm{Ac})$. These samples would comply with current regulations for using as additives in food applications, according to the United States Code of Federal Regulation (2017) that considers acetylated starches can be used with a maximum of $2.5 \%$ acetyl groups.

With trials performed using concentrations acetic anhydride greater than $12 \mathrm{~g} / 100 \mathrm{~g}$ starch, \%Ac values between 3.04 and 5.90 were obtained, corresponding to DS values between 0.12 and 0.23 .

Similar results were obtained by Osundahunsi et al. [10], who used different concentrations of acetic anhydride and obtained acetylated sweet cassava starch with Ac\% values between 0.89 and 5.35. Annison et al. [19] suggest that acetylated starches of DS between 0.20 and 0.25 have potential value as ingredients for enhancing the nutritional aspects of foods as they have been shown to be able to selectively raise fatty acids of short levels chain in the large bowel.

Table 1: Relationship of percentage of acetyl groups (\%Ac) and degree of substitution (DS) of acetylated starches with low DS and experimental conditions applied.

\begin{tabular}{|c|c|c|c|c|c|}
\hline \multirow[b]{2}{*}{$\begin{array}{c}\text { Sample } \\
\text { identification }\end{array}$} & \multicolumn{3}{|c|}{ Experimental conditions } & \multirow[b]{2}{*}{$\% A c$} & \multirow[b]{2}{*}{ DS } \\
\hline & $\begin{array}{l}\text { g acetic anhydride } \\
/ 100 \mathrm{~g} \text { starch }\end{array}$ & $\begin{array}{l}\text { Starch/water } \\
\text { ratio }(\mathbf{g} / \mathbf{g})\end{array}$ & $\begin{array}{l}\text { Reaction } \\
\text { time } \\
\text { (min) }\end{array}$ & & \\
\hline NS & 0 & - & - & - & - \\
\hline $\mathrm{AS}_{0.04}$ & 2 & $1 / 2.25$ & 30 & $1.05 \pm 0.06^{\mathrm{a}}$ & $0.040^{\mathrm{a}}$ \\
\hline $\mathrm{AS}_{0.06}$ & 4 & $1 / 2.25$ & 30 & $1.58 \pm 0.03^{b}$ & $0.060^{b}$ \\
\hline $\mathrm{AS}_{0.07}$ & 8 & $1 / 2.25$ & 30 & $1.79 \pm 0.05^{\mathrm{c}}$ & $0.070^{c}$ \\
\hline $\mathrm{AS}_{0.08}$ & 6 & $1 / 2.25$ & 30 & $2.03 \pm 0.06^{d}$ & $0.080^{d}$ \\
\hline $\mathrm{AS}_{0.10}$ & 10 & $1 / 2.25$ & 30 & $2.50 \pm 0.02^{\mathrm{e}}$ & $0.100^{\mathrm{e}}$ \\
\hline $\mathrm{AS}_{0.12}$ & 12 & $1 / 2.25$ & 30 & $3.04 \pm 0.04^{\dagger}$ & $0.120^{f}$ \\
\hline $\mathrm{AS}_{0.14}$ & 14 & $1 / 2.25$ & 30 & $3.69 \pm 0.01^{g}$ & $0.140^{\mathrm{g}}$ \\
\hline $\mathrm{AS}_{0.17}$ & 20 & $1 / 2.25$ & 30 & $4.40 \pm 0.06^{h}$ & $0.170^{\mathrm{h}}$ \\
\hline
\end{tabular}

* NS is Native Starch and AS is Acetylated Starch. Subscripts indicate the sample substitution degree.

** Values with different superscripts in column are significantly different $(p<0.05)$.

*** Mean values were obtained from duplicate measurements.

In the acetylation of cassava starch, when the reaction time or the anhydride concentration were increasing in amounts necessary to obtain DS greater than 0.2 a paste with too high viscosity was formed dificulting the continuity of the reaction. For this reason, to achieve DS> 0.2 the Mark and Mehltretter [14] method was used.

\section{b) Degree of substitution $>0.2$}

Using Mark and Mehltretter [14] method acetylated starches up to DS=1.36 were obtained. Values of \%Ac and DS are shown in Tables 2 and 3, which correspond to experiments that were carried out using 
as reaction variables the concentration of catalyst (Table 2) and reaction time (Table 3). Values shown in Table 2 and 3 are means of triplicate determinations \pm standard deviation.

Table 2: Percentage of acetyl groups (\%Ac) and degree of substitution (DS) of acetylated starches with DS>0.2 when the incorporated amount of $\mathrm{NaOH}$ is variable.

\begin{tabular}{|c|c|c|c|c|c|}
\hline \multirow[b]{2}{*}{$\begin{array}{c}\text { Sample } \\
\text { identification }\end{array}$} & \multicolumn{3}{|c|}{ Experimental conditions } & \multirow[b]{2}{*}{$\%$ Ac } & \multirow[b]{2}{*}{ DS } \\
\hline & $\begin{array}{c}\text { g NaOH } / \mathbf{g} \\
\text { starch }\end{array}$ & $\begin{array}{c}\text { Starch/water } \\
(g / g)\end{array}$ & $\begin{array}{c}\text { Reaction } \\
\text { time (min) }\end{array}$ & & \\
\hline $\mathrm{AS}_{0.41}$ & 0.050 & $1 / 2$ & 30 & $9.94 \pm 0.46^{a}$ & $0.41 \pm 0.02^{a}$ \\
\hline $\mathrm{AS}_{0.89}$ & 0.090 & $1 / 2$ & 30 & $19.19 \pm 0.38^{b}$ & $0.89 \pm 0.02^{b}$ \\
\hline $\mathrm{AS}_{1.03}$ & 0.102 & $1 / 2$ & 30 & $21.58 \pm 0.23^{c}$ & $1.03 \pm 0.01^{c}$ \\
\hline $\mathrm{AS}_{1.28}$ & 0.204 & $1 / 2$ & 30 & $25.51 \pm 0.85^{d}$ & $1.28 \pm 0.06^{d}$ \\
\hline
\end{tabular}

* AS is Acetylated Starch. Subscripts indicate the sample substitution degree.

${ }^{* *}$ Values with different superscripts in column are significantly different $(p<0.05)$.

*** Mean values were obtained from duplicate measurements.

From the results shown in the Table 2 the variation of substitution degree as a function of the catalyst concentration is not linear in this range. A greater slope is observed when the concentrations are small and as the concentration of the same increases, the variation of the DS is smaller. On the other hand, variation of DS as a function of the reaction time is approximately linear.

$\mathrm{Xu}$ et al. [2] working with high amylose corn starch $(70 \%)$ carried out the acetylation reaction varying the concentration of $\mathrm{NaOH}$ added, between 0.15 and 0.34 (g NaOH (50\%)/g 100 starch) and obtained DS between 1.65 and 2.59. Unlike cassava starch, in the variation of DS with respect to catalyst concentration was approximately linear.

Table 3: Percentage of acetyl groups (\%Ac) and degree of substitution (DS) of acetylated starches with DS $>0.2$ when the reaction time is variable.

\begin{tabular}{|c|c|c|c|c|c|}
\hline \multirow[b]{2}{*}{$\begin{array}{c}\text { Sample } \\
\text { identification }\end{array}$} & \multicolumn{3}{|c|}{ Experimental conditions } & \multirow[b]{2}{*}{$\% A c$} & \multirow[b]{2}{*}{ DS } \\
\hline & $\begin{array}{l}\text { g NaOH } \\
\text { /g starch }\end{array}$ & $\begin{array}{c}\text { Starch/water } \\
(g / g)\end{array}$ & $\begin{array}{l}\text { Reaction } \\
\text { time (min) }\end{array}$ & & \\
\hline $\mathrm{AS}_{0.72}$ & 0.10 & $1 / 3$ & 30 & $16.20 \pm 0.66^{a}$ & $0.72 \pm 0.03^{a}$ \\
\hline $\mathrm{AS}_{0.75}$ & 0.10 & $1 / 3$ & 60 & $16.66 \pm 0.79^{a}$ & $0.75 \pm 0.04^{a}$ \\
\hline $\mathrm{AS}_{1.04}$ & 0.10 & $1 / 3$ & 105 & $21.74 \pm 0.69^{b}$ & $1.04 \pm 0.04^{b}$ \\
\hline $\mathrm{AS}_{1.36}$ & 0.10 & $1 / 3$ & 240 & $26.75 \pm 0.92^{c}$ & $1.36 \pm 0.06^{c}$ \\
\hline
\end{tabular}

* AS is Acetylated Starch. Subscripts indicate the sample substitution degree.

** Values with different superscripts in column are significantly different $(p<0.05)$.

*** Mean values were obtained from duplicate measurements.

Mello El Halal et al. [8] acetylated barley starch under similar conditions with $\mathrm{NaOH}$ catalyst concentrations of $11 \%, 17 \%$ and $23 \%$ and obtained DS $0.08,0.22$ and 0.31 respectively. Comparing ours results with the obtained in barley starch using similar reaction condition, lower DS are obtained in cassava starch, while in corn starch DS was significantly higher. These results shown the high sensitivity of the substitution reaction to the botanical origin of the raw material.

\section{FTIR Analysis}

Native and acetylated starches were characterized by FTIR in order to verify incorporation of acetyl groups to cassava starch. In Figure 1, the results obtained are presented. 


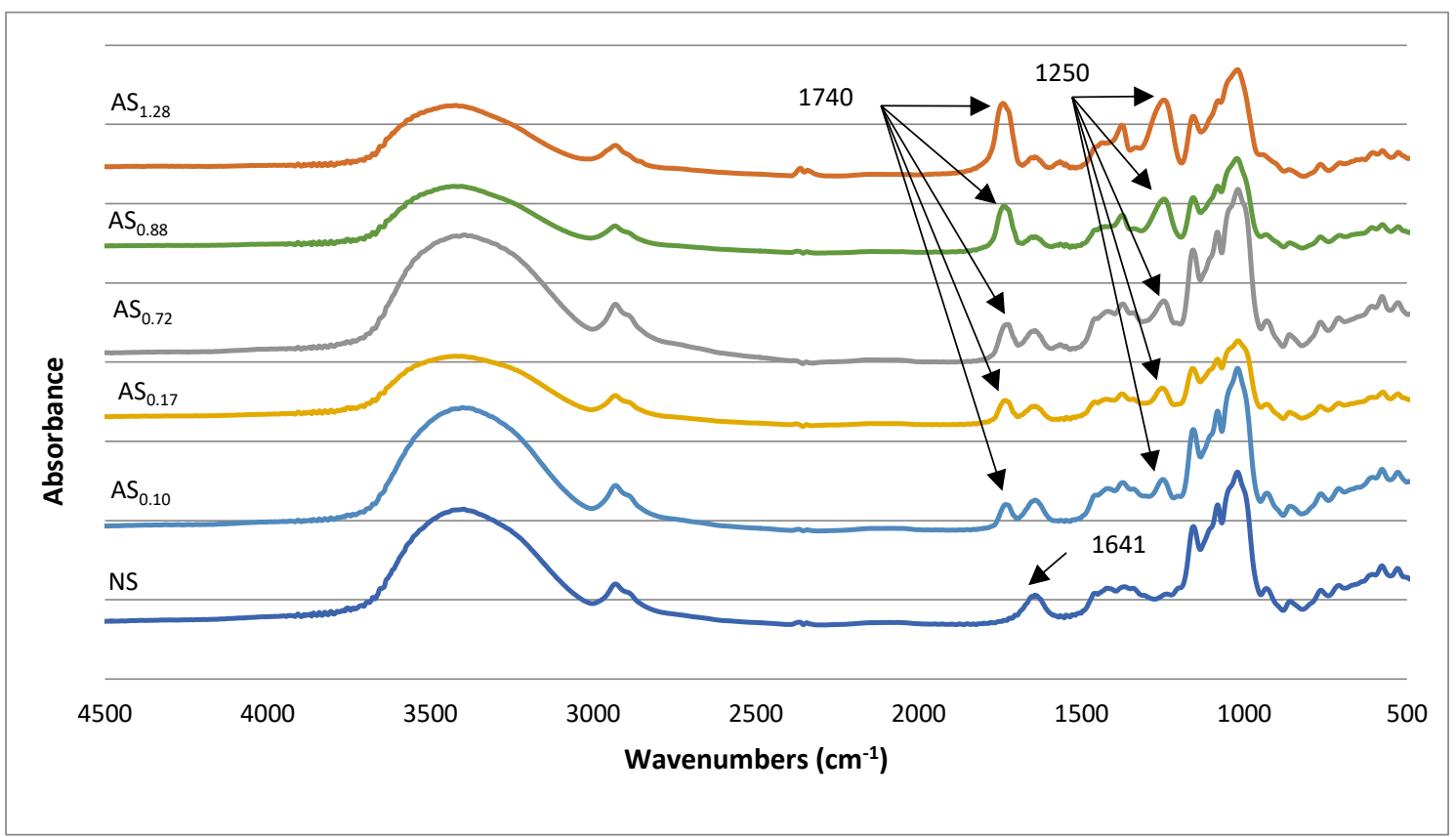

Figure 1. FTIR spectrum of native and acetylated cassava starches (NS: Native Starch; AS: Acetylated Starch).

In native starch characteristic absorption peaks were observed: around $1656-1640 \mathrm{~cm}^{-1}$ associated with angular O-H bending of water molecules [20], about $2960 \mathrm{~cm}^{-1}$ peak is attributed to $\mathrm{C}-\mathrm{H}$ vibration and a broad band around $3450 \mathrm{~cm}^{-1}$, resulting from the vibration of the hydroxyl group. After the acetylation reaction, new absorption bands appeared: at $1250 \mathrm{~cm}^{-1}$, corresponding to the C-O stretching; a signal close to $1400 \mathrm{~cm}^{-1}$ due to asymmetric $\mathrm{CH}_{3}$ vibration and a peak at $1740 \mathrm{~cm}-1$ assigned to the $\mathrm{C}=\mathrm{O}$ of carbonyl.

As seen in Figure 1, height and area of the peaks at 1250 and $1740 \mathrm{~cm}^{-1}$ are greater in the samples with larger DS, while the peak at $1645 \mathrm{~cm}^{-1}$ is reduced. This is because the increase in the degree of substitution implies the replacement of polymer hydroxyl groups by carbonyl groups from the anhydride. Similar results were reported by Diop et al. [12].

In studies carried out on other acetylated starches (potato, corn, barley, oat), these characteristic absorption bands are also observed [2, 5, 21, 22, 23]. These new absorption bands suggest that carbonyl ester groups were formed during the esterification process of the starch, obtaining acetylated starch product [24].

\section{Swelling power (SP) and water solubility index (WSI)}

Figure 2 shows the results of swelling power at different temperatures for native and acetylated starch. Results indicate significant increase in swelling power as the temperature increases in native and acetylates starches of low DS (up to 0.2 ), in agreement with other studies [10, 22, 25, 26]. Also native starch presented lower SP than the acetylated starches for these range of DS.

Maximum values of SP were observed in the DS range between 0.08 and 0.2 in the temperature range of this study. For DS $>0.43$ swelling power values does not increase with the degree of substitution and becomes independent of temperature. This could be explained because a significantly increasing on the number of acetyl groups reduced the interaction of the polymer chains with water molecules, this effect being greater than that produced by the opening of the granule. Similar results were observed by Diop et al. [12] for higher DS values. 


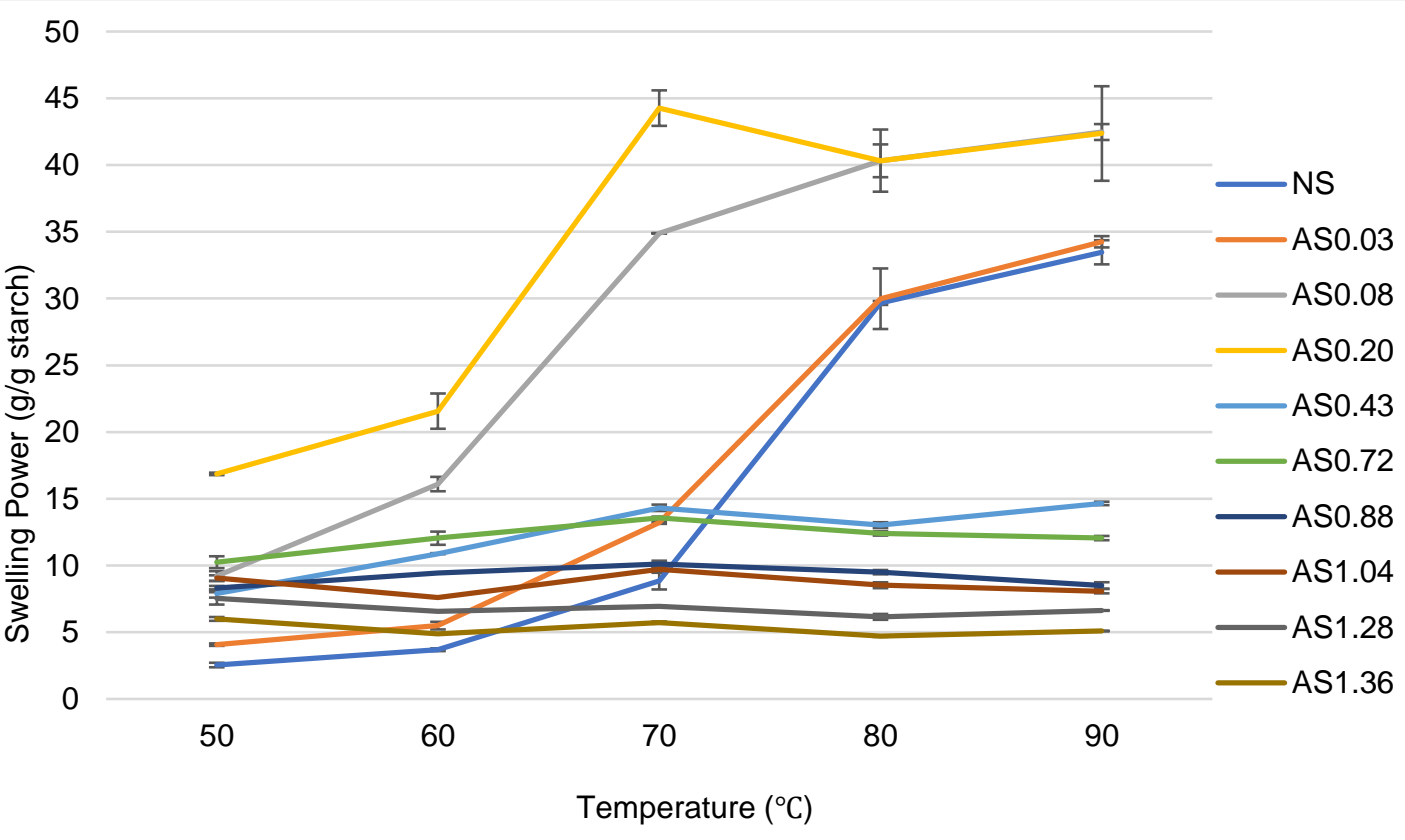

Figure 2. Swelling power of native and acetylated starches of different temperature (NS: Native Starch; AS: Acetylated Starch).

Figure 3 shows that increasing the DS also increases the WSI, reaching a maximum value for acetylated starch with a DS $=0.72$ in the temperature range of this study. For DS> 0.72 , a decreasing the WSI of acetylated starch was observed. This decrease solubility of acetylated starch can be attributed to the replacement of hydroxyl groups by acetyl groups which are more bulky and provide greater hydrophobicity in the starch molecule, due to the lower affinity with water [16].

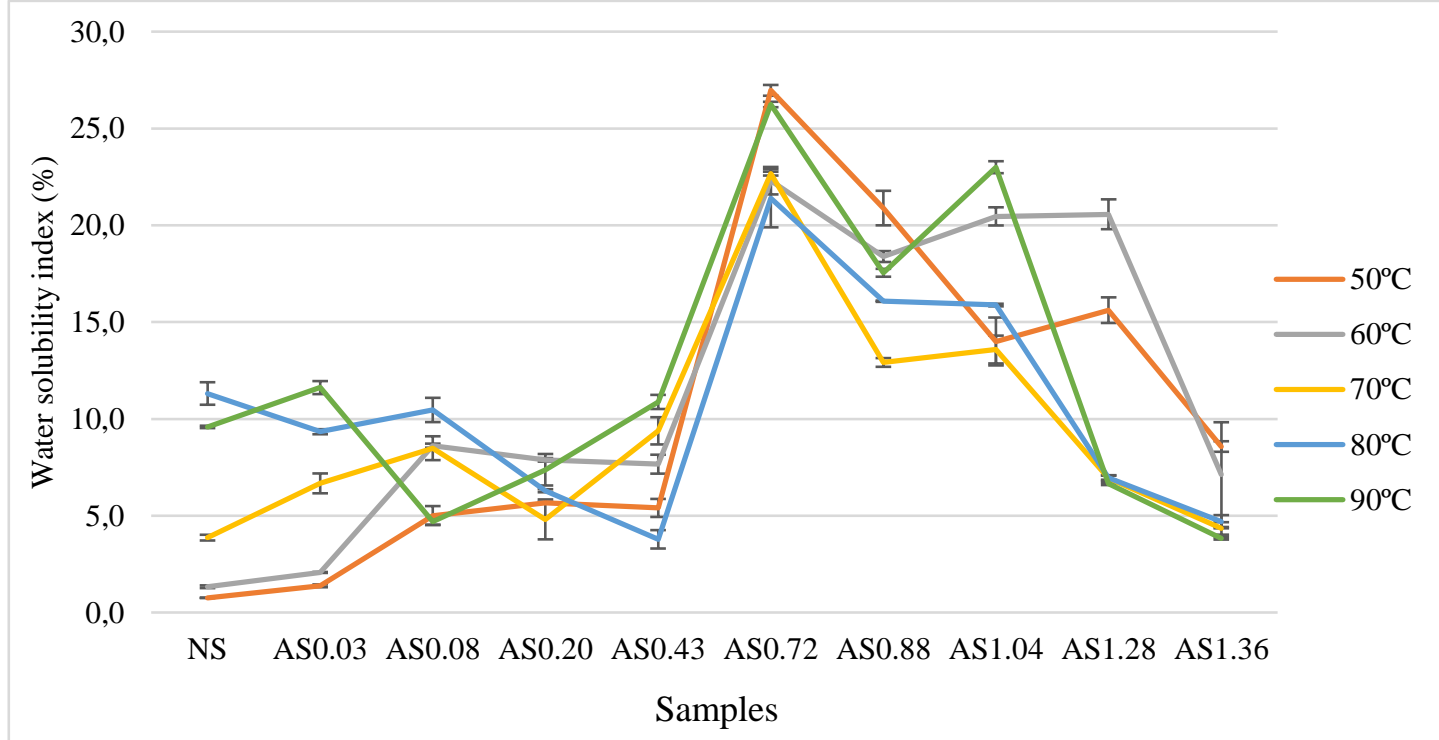

Figure 3. Solubility native and acetylated starches of different temperature (NS: Native Starch; AS: Acetylated Starch).

SP and WSI depends on degree substitution, temperature and also the origin of starch (amylose and amylopectin ratio, granule size, chain length), this explains the fluctuations in the observed values of SP and WSI between different published works.

\section{Scanning electron microscopy (SEM)}

Micrographs of native and acetylated cassava starches are shown in Figure 4. It can be seen the native starch granules have spherical shapes, smooth surfaces, some are truncated and others look like flakes. In some areas of the micrographs, cluster of the starches granules were observed. Similar observations of cassava starch granules have been reported by Mbougueng et al. [9]. 
Granules of acetylated starch with $\mathrm{DS}=0.56$ did not show morphological differences with respect to native starch. In micrographs of starch with $\mathrm{DS}=0.84$ greater formation of conglomerates was observed. Starch with $\mathrm{DS}=1.35$ presented, in addition to cluster formation, loss of structure and appearance of surface roughness, which may be due to the fact of the acetylation reaction is carried out under more drastic conditions, with higher reactant concentration and longer reaction time. Similar results were reported by Xu et al. [2] and Sodhi and Singh [6].

Granules deformation could be due to the incorporation of ester groups that increase the internal molecule volume and reduce the intermolecular tension caused by the hydrogen bonds, producing opening of the granule structure. These morphological transformations could be cause of granule disruption during the heating processing and formation of the clusters [12]. The loss of structure observed as DS increases, has also been observed by different authors in rice, corn and potato starches [7, 10, 12, 21].
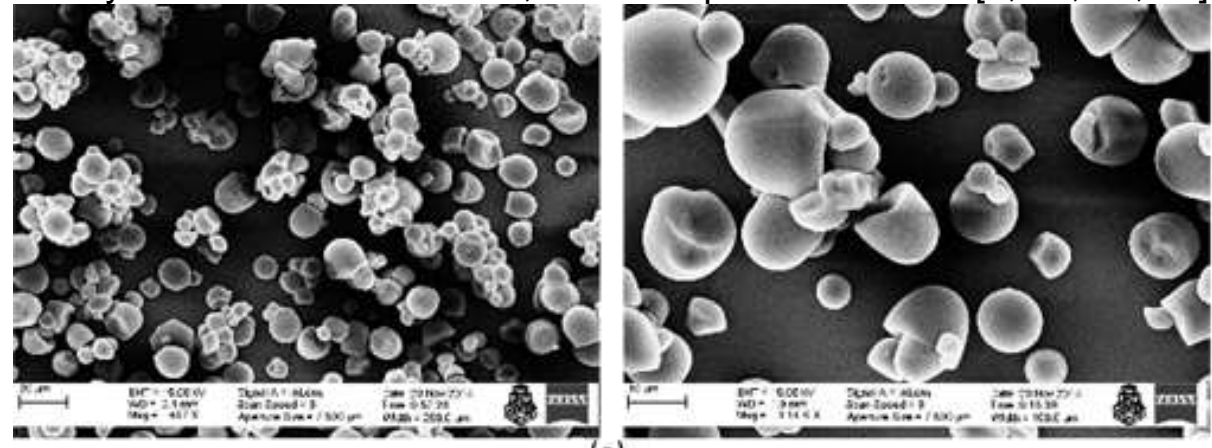

(a)
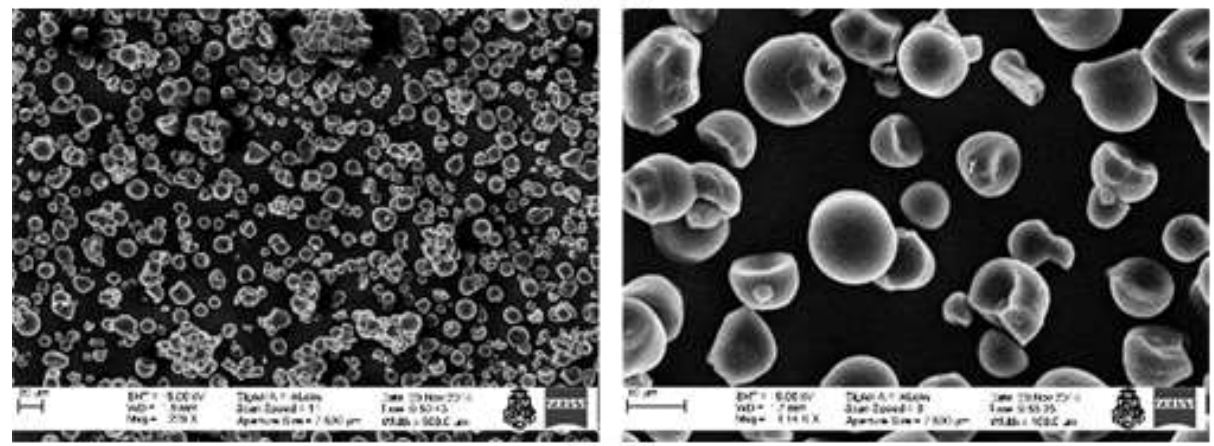

(b)
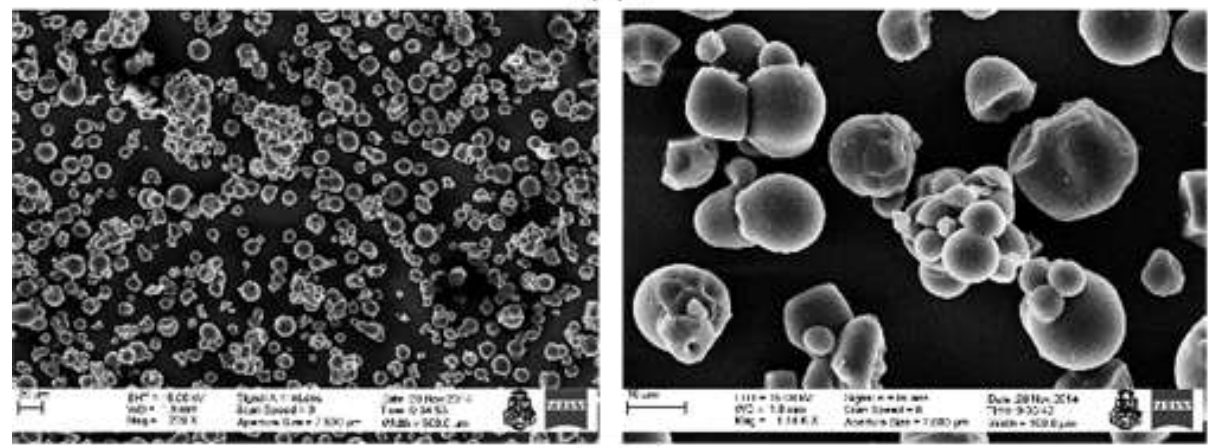

(c)
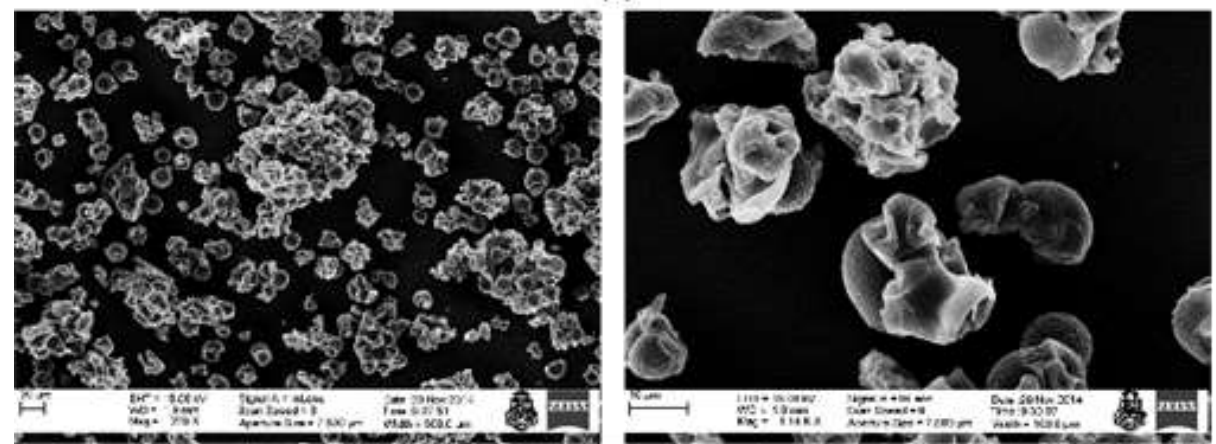

(d)

Figure 4. Scanning electron micrographs (SEM) of native and acetylated starches with two magnifications: $457 \mathrm{X}$ (on the left) and $1140 \mathrm{X}$ (on the right): (a) Native starch, acetylated starches (b) DS=0.56, (c) DS=0.84 and (d) DS=1.35. 


\section{Moisture sorption isotherm}

GAB model describes the sorption behavior in aw range between 0.1 and 0.9 . Table 4 shows values of the model constants, $X_{m}, c$ and $k$, for native and acetylated starches with different degree of substitution. It is observed that the average value of the monolayer moisture content $\left(X_{m}\right)$ tends to decrease with increase of DS. Although there was observed dependence of $X_{m}$ with the DS, no significant differences were registered between sample of native and acetylated starch with lower DS (0.08). Lower monolayer values of a product indicate the greater storage stability [10].

The moisture content increased with the increase in equilibrium water activity. As is known, the acetyl group is more hydrophobic than the hydroxyl group of the anhydroglucose unit, so the native starch absorbed more moisture than acetylated starches, and with the increasing of the DS the moisture absorption decreased.

Experimental results for aw $=0.90$ indicated the native starch had an equilibrium moisture content of approximately $0.20 \mathrm{~g} / \mathrm{g}$ dry starch, while the equilibrium moisture content of the acetylated starch with DS=1.2 was $0.17 \mathrm{~g} / \mathrm{g}$ dry starch.

Tendency to increase the $k$ values with the increase of DS was observed, however there was not significant differences. These results in agreement with those reported for starchy foods in other works [27].

On the other hand, c constant values were a lower in the acetylated than native starch.

Table 4. Estimated values of GAB model and clarity for native and acetylated starches.

\begin{tabular}{ccccccc}
\hline Samples & $\mathbf{X m}(\mathbf{g} / \mathbf{g})$ & $\boldsymbol{c}$ & $\boldsymbol{k}$ & $\mathbf{R}^{2}$ & MPE & Clarity \\
\hline NS & $0.085 \pm 0.004^{\mathrm{d}}$ & $16.56 \pm 0.34^{\mathrm{c}}$ & $0.69 \pm 0.04^{\mathrm{a}}$ & 99.85 & 2.02 & $9.46 \pm 0.20^{\mathrm{d}}$ \\
$\mathrm{AS}_{0.04}$ & - & - & - & - & - & $19.07 \pm 0.28^{\mathrm{a}}$ \\
$\mathrm{AS}_{0.08}$ & $0.081 \pm 0.002^{\mathrm{d}}$ & $14.29 \pm 0.97^{\mathrm{b}}$ & $0.70 \pm 0.09^{\mathrm{a}}$ & 98.78 & 3.64 & $14.09 \pm 0.08^{\mathrm{f}}$ \\
$\mathrm{AS}_{0.17}$ & - & - & - & - & - & $12.29 \pm 0.19^{\mathrm{e}}$ \\
$\mathrm{AS}_{0.43}$ & - & - & - & - & - & $0.89 \pm 0.09^{\mathrm{c}}$ \\
$\mathrm{AS}_{0.72}$ & - & - & - & - & - & $0.72 \pm 0.07^{\mathrm{b}}$ \\
$\mathrm{AS}_{0.88}$ & $0.071 \pm 0.005^{\mathrm{c}}$ & $12.90 \pm 0.90^{\mathrm{a}, \mathrm{b}}$ & $0.74 \pm 0.03^{\mathrm{a}}$ & 98.95 & 3.82 & $0.51 \pm 0.06^{\mathrm{a}}$ \\
$\mathrm{AS}_{1.04}$ & $0.069 \pm 0.004^{\mathrm{b}}$ & $11.24 \pm 1.54^{\mathrm{a}}$ & $0.72 \pm 0.02^{\mathrm{a}}$ & 98.21 & 4.10 & $0.50 \pm 0.03^{\mathrm{a}}$ \\
$\mathrm{AS}_{1.28}$ & $0.059 \pm 0.005^{\mathrm{a}}$ & $11.94 \pm 0.02^{\mathrm{a}}$ & $0.77 \pm 0.04^{\mathrm{a}}$ & 96.69 & 4.56 & $0.52 \pm 0.08^{\mathrm{a}}$ \\
$\mathrm{AS}_{1.36}$ & - & - & - & - & - & $0.72 \pm 0.05^{\mathrm{b}}$ \\
\hline
\end{tabular}

* NS is Native Starch and AS is Acetylated Starch. Subscripts indicate the sample substitution degree

** Values with similar superscripts in column are not significantly different $(p<0.05)$.

${ }^{* * *}$ All values are means of triplicate determinations \pm standard deviation means.

\section{Starch pasting properties}

\section{Paste clarity}

Light Transmittance values $(\mathrm{T})$ of native and acetylated starch pastes are shows in Table 4. Acetylated starches with low DS, obtained by Wurzburg method, presented higher transmittance values than native starch. These values decreased as DS increased, indicating that acetylated starch of low DS form clearer paste than native starch. Similar results have also been reported in wheat, corn and potato starch after acetylation [23, 28]. Mbougueng et al. [9] also observed a significant increase in clarity of cassava and potato acetylated starch with DS below 0.3. After gelatinization of the acetylated starch, polymer chains resulting from the granule destruction would have a lower association than those of native starch, due to substitution of $\mathrm{OH}$ by acetyl groups that causes greater repulsion between the adjacent chains. If there is also a smaller amount of remaining grains, the pastes obtained would be more transparent. Which would explain the increase of $\mathrm{T}$ in the acetylated starches until $\mathrm{DS}=0.17$.

Otherwise, starches pastes with higher DS (DS > 0.5) obtained by method of Mark and Mehltretter [14] presented transmittance values significantly lower than native starch. Same trend was obtained in wheat, corn and potato starches [28]. 


\section{Viscoamylographic test}

Properties of native and acetylated starch, analyzed with a Brabender viscoamylograph are shows in Table 5. Pasting temperature values of acetylated starches were lower than that of native starch, decreasing as the acetyl groups content increased. Reduction in gelatinization temperature of acetylated starch could be due to the incorporation of acetyl groups in the starch structure, causing the reduction of attractive forces in amorphous region and weaken the intramolecular hydrogen bonds in the granule [8]. This feature is one of the advantages achieved with acetylation, since it allows the use of acetylated starches as a thickening agent in processes where lower gelatinization temperatures are required, and in addition, to reduce energy costs during the manufacture of these products.

Table 5. Pasting properties of native and acetylated starches.

\begin{tabular}{|c|c|c|c|c|c|c|}
\hline \multirow{2}{*}{ Parameters } & \multirow{2}{*}{$\begin{array}{l}\text { Native } \\
\text { starch }\end{array}$} & \multicolumn{5}{|c|}{ Acetylated starch } \\
\hline & & $\mathrm{AS}_{0.04}$ & $\mathrm{AS}_{0.08}$ & $\mathrm{AS}_{0.20}$ & $\mathrm{AS}_{0.88}$ & $\mathrm{AS}_{1.28}$ \\
\hline Pasting temperature (PT), ${ }^{\circ} \mathrm{C}$ & $60.3 \pm 0.1^{d}$ & $59.9 \pm 0.5^{\text {c.d }}$ & $56.8 \pm 0.2^{b}$ & $54.2 \pm 0.5^{a}$ & $53.5 \pm 0.3^{a}$ & nd \\
\hline Peak Viscosity (PV), UB & $384.0 \pm 14.1^{\mathrm{a}}$ & $355.3 \pm 12.1^{b}$ & $356.5 \pm 0.7^{b}$ & $385.0 \pm 6.5^{\mathrm{a}}$ & $\mathrm{np}$ & nd \\
\hline $\begin{array}{l}\text { Hot paste viscosity (HPV), } \\
\text { UB }\end{array}$ & $152.5 \pm 2.1^{\mathrm{b}}$ & $133.7 \pm 4.9^{a}$ & $192.0 \pm 1.4^{\mathrm{c}}$ & $157.0 \pm 3.3^{b}$ & $262 \pm 5.9^{d}$ & nd \\
\hline $\begin{array}{l}\text { Cool paste viscosity (CPV), } \\
\text { UB }\end{array}$ & $277.5 \pm 2.1^{b}$ & $240.0 \pm 3.6^{a}$ & $330.5 \pm 4.9^{c}$ & $244.0 \pm 3.4^{\mathrm{a}}$ & $400 \pm 7.2^{d}$ & nd \\
\hline Breakdown (BD), UB & $106.5 \pm 12.0^{a}$ & $115.3 \pm 14.9^{a . b}$ & $126.0 \pm 4.2^{b}$ & $141.0 \pm 7.5^{\mathrm{c}}$ & - & nd \\
\hline Setback (SB), UB & $125.0 \pm 1.4^{c}$ & $106.3 \pm 1.5^{b}$ & $138.5 \pm 6.4^{d}$ & $87.0 \pm 5.2^{a}$ & $138 \pm 4.6^{d}$ & nd \\
\hline
\end{tabular}

*Values with different superscripts in line are significantly different $(p<0.05)$.

${ }^{* *}$ All values are means of triplicate determinations \pm standard deviation means.

${ }^{* \star *}$ np: no peak ; nd: not detected.

Pasting properties of the acetylated starches showed a variable behavior linked to DS, in agreement with other researches $[6,21]$. The results of the viscosity measurements of HPV and CPV showed maximum values at DS equal to 0.88 . These viscosity values are also higher than those measured for native starch, as seen in Table 5. Hot paste viscosity has been reported to be influenced by the extent of amylose leaching, friction between swollen granules, granule swelling, among others [29].

Experimental values of breakdown systematically increased with the DS until 0.2. At higher DS (0.88), the curve presents regular viscosity increases, without viscosity peak formation. This pattern could be due to higher resistance to heat and shear by the high substitution degree in the acetylated cassava starch as it has been reported in barley starch by Bello-Perez et al. [21].

In the case of the starch with the highest DS $\left(\mathrm{AS}_{1.28}\right)$ the amylogram was almost horizontal line, without presenting the peaks that usually characterize the parameters of starch pastes.

\section{CONCLUSION}

Acetylated starches with substitution degrees between 0.04 and 1.36 were prepared from cassava starch.

To obtain acetylated starches with DS up to 0.2 was possible by a mild reaction in aqueous medium and room temperature. Due to high viscosity of cassava starch suspension this method was impractical to achieve higher degree of substitution values and a method with more drastic conditions was required (higher temperature, highest ratio of starch / acetic anhydride and more concentrated $\mathrm{NaOH}$ solution). The incorporation of acetyl groups to the polymer chain was clearly visualized in the FTIR diagrams by the increment of the peaks corresponding to $\mathrm{C}-\mathrm{O}$ stretching, asymmetric $\mathrm{CH}_{3}$ vibration and $\mathrm{C}=\mathrm{O}$ of carbonyl.

The values of solubility and swelling of the acetylated starches increased with the increase in the degree of substitution until reaching a maximum, then the behavior was reversed, showing the typical behavior of mechanisms with opposite effects that predominate in different ranges of substitution degree. An additional advantage of acetylated cassava starch is that obtained pastes have greater clarity than the native starch pastes, in the range of degrees of substitution less than 0.2. SEM micrographs showed that as acetyl groups are incorporated, the granules suffer superficial changes and eventually lose their structure for DS $>1.3$.

Reduction in gelatinization temperature of acetylated starch with the increase of substitution degree was observed. This feature is one of the advantages achieved with the acetylation of cassava starch, since it 
allows the use of acetylated starches as a thickening agent in processes where low gelatinization temperatures are required.

\section{REFERENCES}

1. Singh J, Kaur L, McCarthy OJ. Factors influencing the physico-chemical, morphological, thermal and rheological properties of some chemically modified starches for food applications (review). Food Hydrocolloids 2007, 21, 122.

2. $\mathrm{Xu}$ Y, Miladinov V, Hanna MA. Synthesis and characterization of starch acetates with high substitution. Cereal Chemistry 2004, 81, 735-740.

3. $\mathrm{Xu}$ YX, Dzenis $\mathrm{Y}$, Hanna MA. Water solubility, thermal characteristics and biodegradability of extruded starch acetate foams. Industrial Crops and Products 2005, 21, 361-368.

4. Biswas A, Shogren RL, Selling G, Salch J, Willett JL, Buchanan CM. Rapid and environmentally friendly preparation of starch esters. Carbohydrate Polymers 2008, 74, 137-141.

5. Singh J, Kaur L, Singh N. Effect of Acetylation on Some Properties of Corn and Potato Starches. Starch/Stärke 2004, 56, 586-601.

6. Sodhi NS, Singh N. Characteristics of acetylated starches prepared using starches separated from different rice cultivars. Journal of Food Engineering 2005, 70, 117-127.

7. Colussi R, Pinto VZ, Mello El Halal SL, Vaniera NL, Villanova FA, Marques e Silva R, da Rosa Zavareze E, Guerra Dias AR. Structural, morphological, and physicochemical properties of acetylated high, medium, and low-amylose rice starches. Carbohydrate Polymers 2014, 103, $405-413$.

8. Mello El Halal SL, Colussi R, Pinto VZ, Bartz J, Radunz M, Villarreal Carreño NL, Guerra Dias AR, da Rosa Zavareze E. Structure, morphology and functionality of acetylated and oxidized barley starches. Food Chemistry 2015, 168, 247-256.

9. Mbougueng PD, Tenin D, Scher J, Tchiégang C. Influence of acetylation on physicochemical, functional and thermal properties of potato and cassava starches. Journal of Food Engineering 2012, 108, 320-326.

10. Osundahunsi OF, Seidu KT, Mueller R. Effect of presence of sulphurdioxide on acetylation and sorption isotherm of acetylated starches from cultivars of cassava. Food Chemistry 2014, 151, 168-174.

11. Larotonda FDS, Matsui KN, Soldi V, Laurindo JB. Biodegradable films made from raw and acetylated cassava starch. Brazilian Archives of Biology and Technology 2004, 47-3.

12. Diop CIK, Li HL, Xie BJ, Shi J. Effects of acetic acid/acetic anhydride ratios on the properties of corn starch acetates. Food Chemistry 2011, 126, 1662-1669.

13. Wurzburg OB (1964). Starch derivatives and modification, in Methods in Carbohydrate Chemistry (4th ed, pp. 286288). Ed. Whistler. Academic Press, New York.

14. Mark AM, Mehltretter CL. Facile preparation of starch triacetates. Die stärke 1972, 3, 73-76.

15. Ogawa K, Hirai I, Shimasaki C, Yoshimura T, Ono S, Rengakuji S. Simple determination of degree of substitution for starch acetate. Bulletin of the Chemistry Society of Japan 1999, 72, 2785-2790.

16. Leach HW, McCowen LD, Schoch TJ. Structure of starch granule. I swelling and solubility patterns of various starches. Cereal Chemistry 1959, 36 (6), 534-544.

17. Piyachomkwan K, Chotineeranat S, Kijkhunasatian C, Tonwitowat R, Prammanee S, Oates CG, Sriroth K. Edible canna (Canna edulis) as a complementary starch source to cassava for the starch industry. Industrial Crops and Products 2002, 16, 11-21.

18. International Starch Institute. ISI 19-6e. Determination of Viscosity of Starch by Brabender. 2000

19. Annison G, Illman RJ, Topping DL. Acetylated, propionylated or butyrylated starches raise large bowel short-chain fatty acids preferentially when fed to rats. Journal of Nutrition 2003, 133 (11), 3523-3528.

20. Melo C, Garcia PS, Grossmann MVE, Yamashita F, Dall'Antônia LH, Mali S. Properties of extruded xanthan-starchclay nanocomposite films. Brazilian Archives of Biology and Technology 2011, 54 (6).

21. Bello-Perez LA, Agama-Acevedo E, Zamudio-Flores PB, Mendez-Montealvo G, Rodriguez-Ambriz SL. Effect of low and high acetylation degree in the morphological, physicochemical and structural characteristics of barley starch. Food Science and Technology 2010, 43, 1434-1440.

22. Shah A, Masoodi FA, Gani A, Ashwar BA. Physicochemical, rheological and structural characterization of acetylated oat starches. LWT - Food Science and Technology 2017, 80, $19-26$.

23. Zhao K, Li B, Xu M, Jing L, Gou M, Yu Z, Zheng J, Li W. Microwave pretreated esterification improved the substitution degree, structural and physicochemical properties of potato starch esters. LWT - Food Science and Technology 2018, 90, 116-123.

24. Chi H, Xu K, Wu X, Chen Q, Xue D, Song C, Zhang W, Wang P. Effect of acetylation on the properties of corn starch. Food Chemistry 2008, 106, 923-928. 
25. Colussi R, Mello El Halal SL, Pinto VZ, Bartz J, Gutkoski LC, da Rosa Zavareze E, Guerra Dias AR. Acetylation of rice starch in an aqueous medium for use in food. LWT - Food Science and Technology 2015, 62, 1076-1082.

26. Zhan F, Liang Y, Tan C, Lu Y, Cui B. Research on the water-holding capacity of pork sausage with acetate cassava starch. Starch/Stärke 2014, 66, 1033-1040.

27. Timmermann EO, Chirife J, Iglesias HA. Water sorption isotherms of foods and foodstuffs: BET or GAB parameters. Journal of Food Engineering 2001, 48, $19-31$.

28. Craig SAS, Maningat CC, Seib PA, Hoseney RC. Starch paste clarity. Cereal Chemistry 1989, 66, 173-182. Olkku J, Rha C. Gelatinization of starch and wheat flour starch-a review. Food Chemistry 1978, 3, $293-317$.

(C) 2020 by the authors. Submitted for possible open access publication under the terms and conditions of the Creative Commons Attribution (CC BY NC) license (https://creativecommons.org/licenses/by-nc/4.0/). 